\title{
Workshop 6: Wider impacts of public transport and successful implementation of desirable and beneficial projects
}

\author{
$\underline{\text { Christo Venter }}^{\mathrm{a}}$ and Wai Yan Leong ${ }^{\mathrm{b}}$ \\ a Department of Civil Engineering and Centre for Transport Development, University of Pretoria, Private Bag X20, \\ Hatfield, Pretoria 0028, South Africa \\ ${ }^{b}$ Land Transport Authority, No. 1 Hampshire Road,219428, Singapore
}

Keywords:

Social impacts of transport; Accessibility; Cost Benefit Analysis; Appraisal; Option value; Agglomeration benefits

\section{ABSTRACT}

This paper reports on topics discussed at workshop 6 of the Fifteenth Conference on Competition and Ownership in Land Passenger Transport (Thredbo 15), in Stockholm. The purpose of the workshop was to consider recent advances in identifying, understanding, and measuring the wider impacts of public transport, defined as those not typically included in assessments of direct user and system costs and benefits. While not all impacts are as yet well understood, progress is being made both conceptually and methodologically. A promising methodological convergence is apparent between disciplines dealing with different aspects of the social value of transport - for instance psychology and geography - and between different possibly overlapping definitions of wider impacts - such as accessibility, option value, and agglomeration benefits. The workshop also delved more deeply into the role of Cost-Benefit Analysis (CBA) and wider impact assessment in decision making. Case studies show that CBA does not inform decisions around project implementation as deeply as it might, and that assessments of wider benefits may open up space for manipulation of outcomes by vested interests. The workshop concluded that more work is needed on appraisal frameworks that are sufficiently transparent and rigorous to avoid abuse, and called for more case studies on the interaction between impact assessment and the political economy of institutions and decision makers.

\section{Acknowledgements}

This paper reports on topics discussed at workshop 6 of the Fifteenth Conference on Competition and Ownership in Land Passenger Transport (called Thredbo 15), Stockholm, Sweden $13^{\text {th }}-17^{\text {th }}$ August 2017. We are indebted to all participants who contributed actively to the 3-day workshop discussions. Workshop participants included Disa Asplund, Anders Bondemark, Graham Currie, Andreas Frank, Erik Johansson, Katrin Lättman, Gail Le Bransky, Waiyan Leong, Nahungu Lionjanga, Anders Ljungberg, Gareth Mills, Panagiotis Papaioannou, Niko-Matti Ronikonmäki, Erik Ronnle, Yena Song, Alastair Stone, Kiyohito Utsunomiya, Christo Venter and Ian Wallis.

\section{Introduction}

This workshop built on the discussion around the wider impacts of public transport started ten years ago at Thredbo 10. The new theme of social exclusion and transport introduced in 2007 reflected an intention to move Thredbo discussions beyond issues of contracting and 
economics towards the wider public policy agenda of transport. The initial focus was narrowly defined around social inclusion, an emerging area of scientific work at the time (Stanley and Lucas, 2009). However the scope of the discussion has widened considerably over the years, reflecting the extent to which the theme has matured. Thredbo 11 moved the discussion from definitional and conceptual to more quantifiable issues. A key finding was that the benefits of building more inclusive transport systems extend beyond the targeted populations (Stanley and Mulley, 2010). This opened up the discussion towards consideration of the wider "goods" brought by public transport investment and operations, and how planning, project appraisal, contracting, and policy should respond - a theme that has been returned to in every subsequent conference.

Thredbo 12 linked social issues with the wider public agenda, including environmental sustainability. This reflected the realisation that many of the same policies that improve social inclusion also carry benefits in terms of green-house gas reduction and economic performance. The workshop however noted that, in contrast to the case with environmental awareness, a deeper understanding of social impacts has not yet pervaded transport planning and project implementation on the ground (Stanley and Lucas, 2013).

Thredbo 13 and 14 explored how the social/equity, environmental, and economic benefits of sustainable public transport should be measured and included in project investment, contract specification, and service decisions. There was general agreement that a strong justification exists for acknowledgment of these wider impacts (both positive and negative), but that consensus had not yet emerged about how this should be done in practice (Mulley and Weisbrod, 2016; Stanley and Lucas, 2014). This is partly due to the diversity of wider impacts considered, the divergent conceptual lenses through which they have been studied, and the wide array of measurement techniques that have been used to study them.

The present workshop continued with the theme of exploring the wider social and economic impacts of projects. Wider impacts were defined as those not typically included in direct assessments of user and system costs and benefits, and therefore often harder to quantify and monetise. The aim was firstly to demonstrate advances in identifying, understanding, and measuring such impacts. While not all impacts are as yet well understood, both conceptual and methodological progress is being made. The rich discussions between participants from diverse disciplines - including psychologists, economists, planners, and engineers suggested that interdisciplinary work might be particularly useful for bridging existing knowledge gaps. As an example, use of psychometric tools for measuring subjectively experienced aspects of accessibility might help to quantify the social value of accessibility enhancements for inclusion in project appraisal. More work is required to sharpen conceptual and empirical tools around areas such as option value and the value of information. Empirical results presented from diverse geographical settings demonstrated how both the type of wider impacts considered and their significance vary by location; more empirical studies from different locations are needed to understand the importance of context.

The workshop also delved more deeply into the question of how decision making should be informed of these wider impacts during project appraisal. It is accepted that Cost-Benefit Analysis (CBA) has certain shortcomings, both as a framework for assessment of strictly monetised impacts, and in terms of its sometimes onerous data demands. These limitations are seen as particularly problematic in relation to this conference's focus on sustainable public 
transport investment, as public transport projects often have larger intangible benefits than roads projects and may thus be more affected by shortcomings in appraisal methodologies. Case studies on actual cost benefit appraisal exercises, some of which included wider benefits, show that an often wide divergence exists between our theoretical understanding of their shortcomings, and their application in practice. This leads to cases where outcomes may appear manipulated to support particular stakeholders' interests, which might lead to a loss of confidence in CBA as a decision support tool among decision makers and the public. The workshop concluded that more work is needed on appraisal frameworks that are sufficiently transparent and rigorous to avoid their abuse by special interests, yet flexible enough to respond to local priorities and evolving theory and data on the direct and wider impacts of transport interventions.

Many papers in this workshop have strong links with workshop 5, which also dealt with the valuation of benefits and costs of public transport, but focussed more strongly on social outcomes (such as social inclusion and quality of life), and how these might practically be translated into mechanisms for funding public transport.

\section{Major themes of discussion}

The papers and discussions in this workshop centred around two main thematic areas. The first dealt with advances in both the theory and the empirical evidence base around the measurement of impacts that are wider than the conventional direct costs and benefits included in project appraisal. The second asked how the practice of project and policy appraisal should respond to these insights on wider impacts, and what pitfalls might be experienced along the way.

\subsection{Defining and measuring wider impacts}

Conventional impact analysis focuses primarily on directly affected groups, including transport users (in terms of savings in travel time and cost, and accident reduction), and transport operators (in terms of operating costs and funding). Initial workshop discussions reflected this focus, with Asplund and Pyddoke examining the welfare impacts of fare and frequency policies for bus services in medium-sized cities. By highlighting how the optimal policy differs depending on whether total welfare maximising or Pareto considerations are applied, their paper previewed subsequent discussions that progressively expanded the scope of benefits in terms of both time frame and affected groups. Some of these wider benefits are enjoyed by system users instantaneously (such as the value of reductions in uncertainty due to real-time information, discussed by Kouroupakis et al.). Broadening the scope of affected groups considered, Mills and White evaluate the benefits of bus-based Park and Ride in the United Kingdom, but consider impacts on both bus and car users travelling on the rest of the network. They show that the benefits of reduced car travel on radial routes could be reduced by additional travel in Park and Ride catchment areas, but that the marginal external benefit of avoided car travel in congested corridors more than offsets the marginal external cost of extra car travel in feeder areas. They illustrate that the overall evaluation of the policy from a costbenefit perspective depends significantly on the contextual assumptions used, in particular correct characterisation of congestion levels in different areas. 
The longer-term perspective automatically broadens the scope of the discussion to include not only current but also potential future users, which is where accessibility as a measure of the potential benefits of transport comes in. Accessibility is understood as a measure of the potential for interaction regardless of whether it is actually used at any point in time. Continuing a theme also explored in Thredbo 14, a number of papers added new dimensions to the assessment of accessibility. Two papers examined changes in accessibility over time, adding a useful longitudinal dimension to understanding the value created by accessibility enhancements. Song et al. found that, in the case of Gwangju in South Korea, planned expansion of the subway system through the opening of a new Line 2 contributed very little to area-wide accessibility due to good coverage of the existing bus and rail system. However, their paper considered improvement in accessibility as a function of travel time reduction, which might perhaps be too narrowly scoping the meaning of accessibility. Similarly, Lionjanga and Venter show that accessibility changes in Johannesburg due to the incremental deployment of a Bus Rapid Transit system are minimal when narrowly measured in terms of travel time isochrones, but more substantial when affordability changes are taken into consideration. They also show that improvements in accessibility do not, on their own, increase the subjective well-being of communities unless people actually use the BRT to access those enhanced opportunities, a finding which raises the question of where the oftentouted non-user benefits come from.

Lättman et al. take the issue of subjective benefits further by measuring people's perceptions of accessibility, and showing that it may not correlate well with conventional objectively measured accessibility metrics. This finding further raises the questions of whether conventional accessibility metrics based on typical indicators like travel time and distance are measuring the right thing, and ultimately which accessibility measures to use for project evaluation. While the intuitive appeal of accessibility as a measure of wellbeing makes it relevant as a policy goal, Frank and Meijer point out that one of the key challenges lies in conveying a fairly complex concept to the layperson. Hence, they suggest that gaming simulations are potentially useful for bringing out commonly excluded perspectives and communicating the benefits of public transport. This might help bridge the gap between transport users and decision makers.

Further widening the discussion, two papers consider the longer-term land use impacts of transit investment through the lens of urban efficiency gains. Le et al. examine the link between transport enhancements measured via accessibility to employment opportunities and property price uplift, taking the North East Line of Singapore's MRT as a case study. They show that the benefits of an investment in heavy rail estimated on the basis of land value uplift and intensification over time can be about 30\% higher than benefits estimated using conventional approaches based purely on generalised cost savings. The additional benefit could be seen as a measure of the wider economic benefit associated with the new MRT line. Their method therefore represents a way of directly monetizing the benefit of accessibility enhancement. Ronikonmäki and Laakso report on similar work in Helsinki, but use effective density (which is similar to a gravity-type accessibility index with a travel time decay function) as a measure of agglomeration, and show that it is positively correlated to productivity.

Bondemark and Johansson extend the idea of accessibility (of a public transport service) to include the notion of option value, noting that both refer to the potential for an individual to reach opportunities, whether they use it or not. On this basis, they argue that the logsum 
accessibility indicator can be used to measure option value, but that it should be supplemented by a risk premium to reflect people's willingness to pay to keep a service available. Utsunomiya demonstrates the quantification of the option value of railways through the use of contingent valuation methods. He finds a relative additional value of local railways over bus-based alternatives in Japan to be between ten and twenty percent, which contains option values and non-user values.

Both papers help to clarify the relationship between option value and accessibility, and suggest ways to monetize option value in order to incorporate it into project appraisal.

\section{$2.2 \quad$ Incorporating wider impacts into decision making}

The second theme moved from considering individual impacts to asking how these should (and do) influence decisions that are made around which projects and policies are desirable to implement. Three interesting papers recount experiences with the use of cost-benefit analysis in actual case studies. Wallis reviews several ex post evaluations of free travel cards for seniors in New Zealand, finding the results to be very sensitive to the way in which intangible benefits are measured. Use of contingent valuation methods to quantify the value of free travel estimates benefits four times higher than those produced by more conventional economic approaches, but, Wallis argues, may exaggerate benefits and reduce the robustness of the results.

Turning to the use of CBA by public authorities, Vigren and Ljungberg assess the extent to which Swedish public transport authorities use CBA in their planning of operations and infrastructure. They find that it is rarely used in practice - a situation that has not changed in the last 13 years. One of the main reasons, they find, is that CBA "does not always give the answers politicians want", which then puts them in a position of having to defend deviations from the CBA-based recommendation to get their preferred projects implemented. This finding raises fundamental questions regarding the role of CBA in investment appraisal: if it does not contribute to robust decision making, does the problem lie with the methodology itself (with all its well-documented assumptions and limitations), or with the way in which it is applied in practice?

The discussions during this workshop suggest that both might be true. Despite the methodological advances being made, conventional CBA still lacks robust and comprehensive techniques for assessing wider impacts, which might be especially important in public transport projects pursuing sustainability goals. This might account for the inconsistency between CBA findings and the projects intuitively preferred by non-technical decision makers, who might have larger policy goals in mind.

But there is also evidence that CBA (whether the strictly conventional variety or incorporating wider impacts) is not always applied to consistently high technical standards (Flyvbjerg, Holm and Buhl, 2002; Mackie and Preston, 1998). This is unpacked by Ronnle's study of the Swedish high-speed rail project. Initial CBA found the project to be heavily uneconomical, prompting some proponents to launch an alternative 'benefit analysis' which included some of the wider benefits discussed in this workshop but disregarded costs. Ronnle recounts how this process is heavily flawed scientifically, and could not serve as a basis for decision making. Yet it served as a tool for building political momentum and securing buy-in from local-level civil 
servants and politicians. The paper implies that CBA may bring procedural benefits to the planning process, in terms of clarifying individual impacts, building constituencies, and making values explicit, that may be just as important as the final numbers.

Although no agreement was reached, some workshop participants expressed a desire to move towards more comprehensive appraisal frameworks capable of reflecting the diversity of direct and wider impacts within the same framework, especially at the level of policy and strategy evaluation. Two papers contributed thoughts in this regard. A paper by Currie et al. suggests a more holistic way of measuring the sustainability performance of public transport, adopting 15 indicators from 4 categories encompassing Environmental, Social, Economic and System Effectiveness. While they use the measure to examine the impact of regulatory arrangements on sustainability performance, the measure itself presents a potentially useful framework for combining various perspectives during appraisal. Stone went further, suggesting that the problems with conventional economic appraisal methodologies reflect a foundational problem with the way transport is planned in urban areas, as both planning approaches and their supporting tools (including CBA) prioritise short-term gains (such as congestion relief) above longer-term costs and impacts (such as land use patterns promoting car dependence). Stone recommends a new theoretical framework, with a foundation narrative that pays more attention to human behaviour and institutional arrangements in order to promote a broader agenda towards liveable, resilient, and sustainable cities.

\section{Discussion and research recommendations}

Some cross-cutting themes emerged from the workshop that are summarised as follows.

\subsection{Need for analytical rigour}

The papers document some recent advances in both theoretical thinking and empirical measurement of the wider interaction between transport and other social systems. Workshop participants agreed that it is important to continue such technical work to improve the rigor and accuracy with which analysts identify and measure wider impacts - even if just for the sake of contributing towards better planning, identifying implementation risk, and ensuring that transport projects play their desired part in promoting social and economic policy goals.

A number of specific analytical issues in need of further work were identified, including:

- The perspective of the transport operator is often neglected when considering wider impacts. More emphasis is needed on issues such as project risk allocation and distributional impacts across different operators. This might be valuable in building broader coalitions to advocate for the implementation of beneficial projects.

- More work is needed on option value, particularly to clarify its relationship to accessibility as a measure of the non-use value of public transport. Work needs to proceed on both the analytical and empirical fronts to provide more case studies of the quantum and nature of option value benefits.

- More critical thinking is required around the need for integrative appraisal frameworks that can help to define and differentiate between the various direct and wider impacts 
of projects and policies. Echoing previous Thredbo workshop findings (Mulley and Weisbrod, 2016; Stanley and Levinson, 2016), Workshop 6 agreed that, to be useful for decision making, appraisal methods should attempt to measure the total economic value of interventions as comprehensively as possible, while concentrating most effort on the impacts that are likely to be more important. However it seems neither possible nor desirable to express all impacts in monetary terms, so an appraisal framework should be able to accommodate both monetisable and non-monetisable effects. Many questions remain regarding how concepts such as accessibility, option value, agglomeration benefits, and risk reduction relate to each other individually, how they relate to conventional consumer surplus, how they can best be measured (whether or not in monetary terms), and how they should be treated in integrated appraisal in order to avoid either double-counting and under-counting of benefits.

- There is also the broader question of whether or how such wider benefits, including the intangible benefits like better perceived accessibility and option value of transport, can be measured. Typically, it is the transport authorities/taxpayer that funds a significant proportion of public transport investment and such costs and subsidies can result in poor-looking financials on the balance sheet, even if the project meets conventional CBA standards. Thus, from the perspective of transport authorities, suggestions on practical ways to extract some of the consumer surplus generated as a result of certain transport system improvements would be desirable (See workshop report 5 (Stanley and Ljungberg) for more on this).

A number of recommendations for further research relate more specifically to the measurement of wider impacts:

- Longitudinal studies using panel data and other time-series data sets are needed to examine path dependence and asymmetry in welfare impacts - for instance that removing a local bus route may not be the negative of adding the same bus route when doing contingent valuation studies.

- There is scope for introducing subjective metrics (e.g. individual perceptions) alongside more objective analyst-driven measures to better understand user values and benefits. For instance, the workshop paper by Kouroupakis et al. shows that the provision of real-time information at bus stops decreases the waiting times perceived by passengers by about $20 \%$. If this reduction is monetized as an economic benefit, the authors estimate that the cost of providing such information is more than off-set by the benefits. But this raises the question of what the economic resource value of perceived (as opposed to actual) time is, and whether it is valid to include the former in cost-benefit valuations. More thinking is required as to the meaning of subjective attributes in the context of appraisal.

- Whereas previous Thredbo workshops have concluded that accessibility is difficult to incorporate directly into economic appraisal due to its definitional plurality (Mulley and Weisbrod, 2016), progress has been made in linking accessibility empirically to other measures of non-user benefit including option value (Bondemark and Johansson) and land value uplift (Le et al.). Further work should clarify if and how accessibility could be fully accounted for in appraisal via these existing concepts.

- Discussions on wider benefits of transport should be linked more to research approaches used by other disciplines such as psychology and health sciences, where outcomes are measured in different ways. One example of this is the large evolving 
literature on the health benefits of active transport, which could provide a model for measuring the value of other social and quality of life impacts of transport projects.

\subsection{Need for case studies from different contexts}

The wider impacts of transport projects or policies vary by location and context - both in type and size. That implies that, despite the need for integrative appraisal frameworks that can help to establish common definitions and boundaries to the assessment of transport benefits and costs, flexibility is needed in terms of the emphasis placed on various impacts according to local circumstances and priorities. Case studies are useful for highlighting this diversity and how they relate to local issues. Case studies also demonstrate sometimes surprising results, as for instance in the case of Johannesburg's Bus Rapid Transit system having much lower welfare benefits than expected. Case studies are thus not just useful for highlighting blind spots in analysis or policy, but could also spark inquiry into how existing theory or standard practices may be further refined.

Some impacts such as environmental externalities may also display considerable variation over short distances, or by the time of day. Future case study work is needed to examine benefits and costs at the micro level (e.g. the impact of changes to individual bus routes, or fare policies), and not just at the system or city level.

\subsection{Need to examine role of cost benefit analysis in decision making}

There is a need for examining the ways in which the analytical aspects of wider impact appraisal interface with public policy, governance, and political economy. The way in which cost-benefit analysis (CBA) is used in decision making has not been studied very much (Eliasson and Lundberg, 2012). The workshop discussions suggested that CBA plays a limited role in some contexts (especially in public transport projects), and that wider impact analysis may even be abused in order to advocate for projects with political rather than technical merit.

CBA, understood as a way of codifying the complexity of the real world, inevitably involves simplification and will always provide an imperfect reflection of reality. It is thus necessary to avoid both a claim to absolutism, and a desire for endless analysis to include all possible effects. The necessary process of making the assumptions and boundaries of the analysis explicit may open up space for a debate around who the affected parties are, what society values, and how to trade off accuracy with analytical pragmatism. One of the commonly cited criticisms of conventional CBA is its failure to consider distributional effects following from its theoretical assumption that winners compensate losers. While widening the analysis to include distributional issues may help clarify stakeholder interests and promote consensus-building between groups with apparently diverging viewpoints, there is also a view that individual project design and appraisal need not be burdened with ensuring a fair distributional outcome, but rather, impacts should be measured and submitted to those in the decision making process who are in the position of effecting distributional policies.

Future research on cost-benefit analysis as a dialogical rather than a technocratic process could help improve our understanding of how it can contribute more positively to the implementation of beneficial projects. More case studies are needed on how institutional arrangements and processes affect appraisal and implementation. In a robust CBA 
framework, the issue of double-counting and under-counting (of benefits) should ideally be minimised, but workshop participants also recognised the realities of working with resource constraints and imperfect information. This then raises the question of how much analysis is enough, and what level of detail and accuracy is needed to effectively inform decision making.

\section{Recommendations for Thredbo 16}

Two recommendations are made for the future treatment of wider impacts in Thredbo conferences.

Firstly, although Workshops 5 and 6 had some divergence in terms of the detailed topics considered (notably, Workshop 5 dealt more in-depth with financing and monetisation of benefits, while Workshop 6 considered appraisal in more detail), there was some amount of overlap concerning the identification and measurement of wider non-conventional impacts. It might be worthwhile to partially merge the two workshops, with combined opening and starting sessions dealing with topics of mutual interest, and then splitting into more specialist subgroups to consider specific technical topics. This way, the benefits of inter-disciplinary interaction could be retained while providing space for more in-depth technical work on certain issues. As with the main conference, these sub-streams should report back to the plenary workshop.

Secondly, there might be benefit in focusing workshop discussions more explicitly on how the appraisal process informs (or doesn't inform) decision making. More case studies on the role of CBA and wider impact analysis within the political economy of organisations and decision making bodies could be very helpful in identifying shortcomings and best practices in the way transport impacts are measured, communicated, and dialogued between analysts and nontechnical audiences.

\section{List of workshop papers}

Asplund, D. and Pyddoke, R. (2017) A new model for fare and frequency policy in urban bus services.

Bondemark, A. and Johansson, E. (2017) Accessibility and uncertainty: the option value of public transport.

Currie, G., Truong, L. and Gruyter, C.D. (2017) Regulatory structures and their Impact on the sustainability performance of public transport in world cities.

Frank, A. and Meijer, S. (2017) Public transport accessibility needs assessment using gaming simulations.

Kouroupakis, G., Nikolaidou, A., Papaioannou, P. and Politis, I. (2017) Real time information at bus stops: assessing user and system benefits from changes in perceived waiting time.

Lattman, K., Olsson, L.E. and Friman, M. (2017) A new approach to accessibility - perceived accessibility versus objectively measured accessibility in daily travel.

Le, H., Wee Liang, L. and Leong, W.Y. (2017) Land enhancement and intensification benefits of investing in an urban rail network.

Lionjanga, N. and Venter, C. (2017) Accessibility and social welfare: a study of the city of Johannesburg.

Mills, G., and White, P. (2017) Evaluating the long-term impacts of bus-based park and ride. 
Ronikonmäki, N. and Laakso, S. (2017) Measuring agglomeration in transport system planning: effective density as a measure in Helsinki region.

Ronnle, E. (2017) Planners' analysis and opportunism - benefit analysis in the Swedish high-speed rail project.

Song, Y., Kim, H. and Lee, K. (2017) Transit network expansion and accessibility implications: A case study of Gwangju metropolitan area, South Korea.

Stone, A. (2017) A radical reappraisal of transport and land market basics.

Utsunomiya, K. (2017) The value of local railways: An approach using CVM.

Vigren, A. and Ljungberg, A. (2017) Public transport authorities' use of cost-benefit analysis in practice.

Wallis, I. (2017) Socio-economic assessment of the NZ 'SuperGold' Free Seniors Travel scheme.

\section{References}

Eliasson, J., Lundberg, M. (2012). Do cost-benefit analyses influence transport investment decisions? Experiences from the Swedish Transport Investment Plan 2010-21. Transport Reviews, 32(1), 29-48.

Flyvbjerg, B., Holm, M. S., Buhl, S. (2002). Underestimating costs in public works projects: Error or lie? Journal of the American Planning Association, 68(3), 279-295.

Mackie, P., Preston, J. (1998). Twenty-one sources of error and bias in transport project appraisal. Transport Policy, 5(1), 1-7.

Mulley, C., Weisbrod, G. (2016). Workshop 8 report: The wider economic, social and environmental impacts of public transport investment. Research in Transportation Economics, 59, 397-400. doi:10.1016/j.retrec.2016.10.011

Stanley, J., Levinson, D. (2016). Workshop 3 report: Sustainable funding sources and related cost benefit measurements. Research in Transportation Economics, 59, 143150.

Stanley, J., Lucas, K. (2009). Special Issue of the Journal of Transport Policy focusing on international perspectives on transport and social exclusion. Transport Policy, 16, 89.

Stanley, J., Lucas, K. (2013). Workshop 6: The public agenda: What is working and what is missing. Research in Transportation Economics, 39(1), 294-299.

Stanley, J., Lucas, K. (2014). Workshop 6 Report: Delivering sustainable public transport. Research in Transportation Economics, 48, 315-322. doi:10.1016/j.retrec.2014.09.058

Stanley, J., Mulley, C. (2010). Workshop report-Social inclusion. Research in Transportation Economics, 29(1), 275-279. 